\title{
PERAN WANITA DALAM PEMBERDAYAAN EKONOMI KECIL: MIKRO KREDIT DI KELURAHAN PETOJO UTARA
}

\author{
Holly Deviarti \\ Jurusan Akuntansi, Fakultas Ekonomi dan Bisnis, Universitas Bina Nusantara \\ Jln. K.H. Syahdan No. 9, Palmerah, Jakarta Barat 11480 \\ Bunda_mustafa@binus.edu
}

\begin{abstract}
Women have a responsibility to meet the basic needs of families, when the husband has not been successful in adequately meeting family needs. Micro credit is taken from the method of Amanah Ikhtiar Malaysia (AIM), and applied in Petojo area, Central Jakarta. AIM Registration need women as participants in the micro-credit. This process begins with data collection on testing the ability of debtors, make arrangements for borrowers to work properly and return the loan. Implementation took place in a period of 1 year and microcredit borrowers are selected from low economy class community. Before granting loans, microcredit and financial records training implementing agencies provide religious discourse about trade. The meeting between executives and micro-credit borrowers are held every week, the show began with a reading of the pledge, read the Koran and religious lectures. The desired results of this activity is full loan repayments, improved morale, improved family economy, but the reality is not as expected, honesty issues, decreased productivity and have became a boomerang for micro credit in Petojo area. Criteria for successful micro-credit application is simple, namely the intention to repay debt with honesty, and good effort in improving the quality of life.
\end{abstract}

Keywords: micro credit, gender issues, women and the economy

\begin{abstract}
ABSTRAK
Perempuan memiliki tanggung jawab untuk memenuhi kebutuhan pokok keluarganya, ketika suami belum berhasil dalam memenuhi kebutuhan keluarga dengan memadai. Mikro kredit diambil dari metode Amanah Ikhtiar Malaysia (AIM), dan diaplikasikan di daerah Petojo, Jakarta Pusat. Pendaftaran AIM membutuhkan perempuan sebagai peserta dalam mikro-kredit. Proses ini dimulai dengan pendaataan pengujian kemampuan debitur, membuat perjanjian untuk peminjam agar bekerja dengan baik dan mengembalikan pinjaman tersebut. Pelaksanaan berlangsung dalam jangka waktu 1 tahun dan peminjam mikro-kredit dipilih dari ekonomi lemah. Sebelum pemberian pinjaman, lembaga pelaksana pelatihan kredit mikro dan catatan keuangan memberikan wacana agama tentang perdagangan. Pertemuan antara eksekutif dan peminjam kredit mikro diadakan setiap minggu, acara dimulai dengan pembacaan ikrar, membaca Quran, dan kuliah agama. Harapan hasil dari kegiatan ini adalah pengembalian pinjaman, perbaikan moral, perbaikan ekonomi keluarga, tetapi kenyataannya tidak seperti yang diharapkan, masalah kejujuran, produktivitas turun dan menjadi bumerang bagi kredit mikro di daerah Petojo. Kriteria sukses aplikasi kredit kecil sebenarnya sederhana, yaitu niat untuk mengembalikan kejujuran dengan utang, dan upaya yang baik dalam meningkatkan kualitas hidup.
\end{abstract}

Kata kunci: kredit mikro, gender issues, wanita dan ekonomi 


\section{PENDAHULUAN}

Menghalalkan hutang sebagai salah satu jalan keluar bagi golongan yang mengalami masalah keuangan. Cara ini diambil agar masyarakat miskin tidak putus asa dalam menjalani kehidupan seharihari untuk memenuhi kebutuhan mereka. Akan tetapi, perbedaan mendasar dalam konsep hutang piutang dalam Islam adalah bahwa hutang piutang dalam Islam merupakan amal kebajikan di antara golongan yang mampu dengan yang tidak mampu supaya terjalin hubungan saling tolong menolong.

Amanah Ikhtiar Malaysia (AIM) didirikan pada 17 September 1987 untuk mengambil alih Proyek Ikhtiar dan mengembangkannya ke daerah-daerah lain. Aplikasi pemberian pinjaman mikro kredit pada AIM dasarnya diambil dari dari pendekatan Grameen Bank di Bangladesh, dengan berbagai penyesuaian kondisi setempat.

Berdasarkan pengalaman penulis yang ikut bergabung dalam kegiatan AIM ini, aplikasi metode ini sangat Islami dan sederhana pelaksanaannya seperti pertemuan mingguan untuk pembayaran angsuran. Berdasarkan laporan tahunan yang dikeluarkan oleh AIM, tingkat keberhasillan mengurangi kemiskinan di daerah-daerah terpencil di Malaysia sudah sangat berhasil, berkat pelaksanaan metode pembiayaan mikro kredit AIM ini.

Metode AIM ini dicoba diaplikasikan di daerah Petojo, yang merupakan sudut perkampungan kota Jakarta yang padat penduduk. Di wilayah ini terdapat 14 RT, didiami 2.966 orang dengan status sosial yang bervariasi. 19\% atau sekitar 570 dari total penduduk hidup di bawah garis kemiskinan. Wilayah ini juga mendapat dana bantuan dari USAID (United States Agency International Development), khususnya masalah kebersihan.

Metode AIM ini disesuaikan dengan kondisi Jakarta, khususnya wilayah Petojo. Metode yang diterapkan AIM adalah pemberian pinjaman pembiayaan mikro kredit yang merupakan salah satu cara untuk meningkatkan perekonomian . Cara dan pendekatan yang digunakan dalam usaha pinjaman pembiayaan adalah melalui pembangunan pribadi (self improvement) individu dan kemudahan pembiayaan.

Setiap anggota dari mikro kredit yang akan memperoleh bantuan pembiayaan mikro kredit, diminta untuk merancang proyek ekonomi masing-masing mengikuti kemahiran dan kemampuan. Apabila semua anggota kelompok setuju atas rancangan proyek bisnis tersebut, maka pembina kumpulan akan menyetujui pembiayaan mikro kredit dalam kelompok tersebut.

Bentuk proyek yang akan dilaksanakan adalah kembali kepada keupayaan, kesanggupan, dan kemahiran. Proyek ini termasuk usaha kecil seperti jualan barang kelontong, menjual makanan masak, kerajinan, peternakan, dan lain sebagainya yang menghasilkan keuntungan. Para anggota diwajibkan mengusahakan berbagai proyek yang memberikan hasil cepat, guna pengembalian hasil pinjaman setiap minggu.

Di samping aktivitas pemberian pinjaman, terdapat juga misi memperbaiki kualitas akhlak individu agar dapat menunjang amanah dan tanggung jawab, baik bagi pendamping pemberi pinjaman ataupun penerima pinjaman. Berdasarkan latar belakang tersebut, maka dapat diidentifikasikan masalah-masalahnya, yaitu (1) Apakah penerapan kredit kecil dengan metode Amanah Ikhtiar Malaysia (AIM) dapat berhasil diterapkan di Jakarta, khususnya wilayah perkotaan di daerah Petojo; dan (2) Apakah terdapat pengaruh positif atas pelatihan pencatatan keuangan dan perbaikan akhlak dalam kelompok masyarakat perkotaan tersebut. 
Berdasarkan kedua identifikasi masalah di atas, maka tujuan utama dari penelitian ini adalah (1) Melaksanakan pengamatan secara langsung atas pelaksanaan metode AIM di Jakarta; dan (2) Menilai perkembangan kemampuan kelompok masyarakat tersebut dalam hal pengelolaan keuangan dan nilai-nilai akhlak yang baik. Manfaat yang diharapkan dari hasil penelitian ini adalah perbaikan kesejahteraan ekonomi keluarga dan mengembalikan nilai-nilai luhur akhlak yang baik, khususnya kejujuran dalam pola kehidupan masyarakat.

\section{METODE PENELITIAN}

Penelitian ini menggunakan metode atau pendekatan survei untuk melihat aplikasi langsung keberhasilan aplikasi metode AIM yang diterapkan. Lokasi penelitian dilakukan di daerah Petojo yang merupakan sudut perkampungan kota Jakarta yang padat penduduk. Populasi penelitian adalah keluarga miskin atau ekonomi lemah sesuai dengan kriteria yang telah ditetapkan. Untuk pengumpulan datanya dilaksanakan tehnik observasi, yaitu pengamatan langsung terhadap pelaksanaan proses pinjaman, pelatihan, dan pengembaliannya. Tahapan riset yang dilakukan, yaitu survei keluarga miskin, wawancara (minat usaha atas modal yang dipinjamkan), membentuk kelompok, pelatihan pengelolaan keuangan sederhana dan mentoring agama, dan evaluasi pengembalian atau pinjaman.

\section{HASIL DAN PEMBAHASAN}

\section{Terminologi dan Konsep Mikro Kredit}

Kontrak hutang atau pinjaman yang disyariatkan dalam Islam bukanlah untuk mengejar keuntungan keuangan, tapi sebaliknya pinjaman merupakan satu instrumen keuangan bagi mencapai kebersamaan dalam kerjasama, semangat persaudaraan, dan tolong menolong dalam masyarakat. Bagi pembiayaan hutang, 4 konsep utama yang digunakan, yaitu al-Bay' bi-Thaman 'Ajil, al-Murabahah, al-Ijarah, dan Qard al-Hasan.

Bay' bi-Thaman 'Ajil merupakan suatu kontrak yang melibatkan pertukaran barang yang mana barang yang menjadi tukaran itu diserahkan dengan segera dan harganya dibayar secara angsuran. $\mathrm{Al}$ Ijarah melibatkan pertukaran barangan dengan perkhidmatan barangan lain. Al-Ijarah mengandung 2 kategori, yaitu atas manfaat dan atas perkhidmatan. Prinsip kontrak al-Murabahah adalah sama dengan bay' bithaman 'ajil, sedangkan qard al-hasan merupakan pinjaman kebajikan dan peminjam hanya perlu membayar semula uang yang dipinjamkan saja tanpa ada bayaran tambahan.

Konsep Amanah Ikhtiar Malaysia (AIM) adalah suatu badan NGO (Non Government), di mana AIM menyediakan pembiayaan hutang dengan prinsip qard al-hasan. Secara operasional, AIM lebih menekankan posisi wanita dibandingkan laki-laki sebagai perwakilan rumah tangga untuk menerima bantuan pembiayaan hutang ataupun sebagai perantara untuk pihak suami (wanita sebagai anggota mikro kredit, walaupun yang bekerja adalah pihak suami). Wanita sangat diutamakan dalam konsep AIM ini dikarenakan sudah terbukti dalam penelitian di Bangladesh atau Malaysia. Ketika suami gagal melaksanakan tanggung jawabnya dalam memberi nafkah keluarganya, maka wanita lebih bertanggung jawab dalam masalah keuangan atau ekonomi keluarga dibandingkan pria dan AIM sangat menaruh perhatian akan kondisi ini.

Pensyariatan prinsip ini terbukti daripada Al Quran dan al Sunnah, Allah berfirman:

"Dan kalau kamu memberikan pinjaman kepada Allah sebagai pinjaman yang baik (Qard al-Hasan), niscaya Allah akan melipatgandakan balasanNYa kepada kamu serta mengampunkan dosa-dosa kamu. (Surah alThaghabun:17) 
Kelebihan yang dimiliki mikro credit metode Amanah Ikhtiar Malaysia dibandingkan dengan aplikasi mikro kredit lainnya adalah menjadi alasan utama mengapa metode ini dicoba diterapkan di Indonesia, yaitu (1) Memiliki persyaratan khusus dengan tingkat minimal penghasilan, (2) Jumlah pinjaman disesuaikan dengan kemampuan bayar balik, (3) Dibuat perjanjian, baik tertulis maupun diucapkan, (4) Pertemuan rutin mingguan per kelompok untuk pengendalian, (5) Diadakan pelatihan untuk meningkatkan skill, dan (6) Khusus wanita.

Konsep yang diterapkan mikro kredit di daerah Kelurahan Petojo Utara pada tahun 2003 adalah tidak jauh berbeda dengan yang diterapkan oleh AIM, dengan sasaran masyarakat yang berpenghasilan tidak lebih dari Rp 750.000 per bulan, maka seleksi calon anggota kredit kecil dilaksanakan dengan target 2 kelompok, yang terdiri atas 5 peserta setiap kelompoknya.

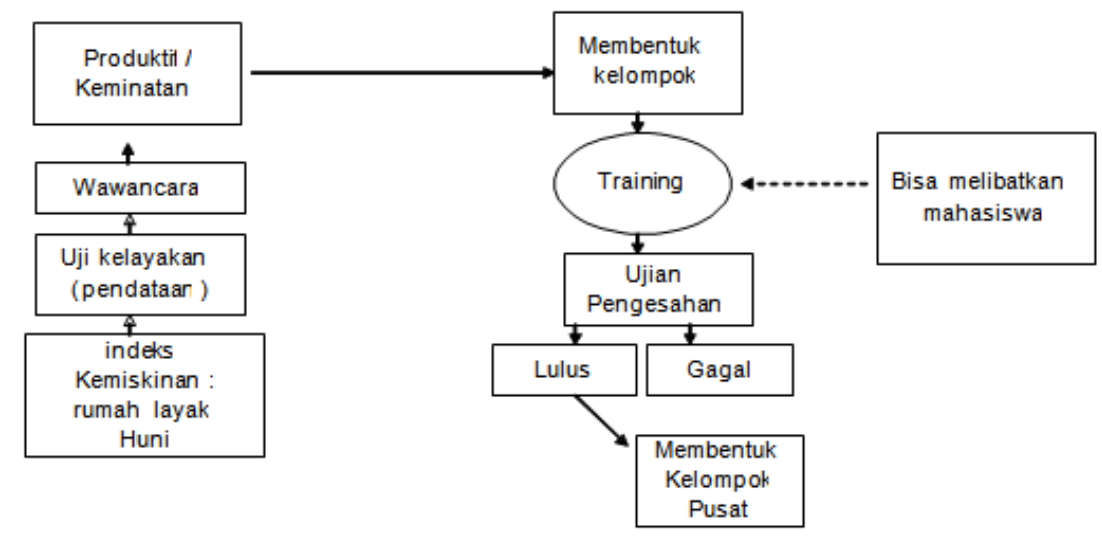

Gambar 1 Flow Chart untuk Mendapatkan Pinjaman

Usaha mikro kredit ini dimulai dengan penyeleksian awal. Penyeleksian awal yang dilakukan adalah melakuan pengisian data pribadi calon anggota, apakah mereka memenuhi prasyarat tingkat kemiskinan kota atau tidak. Apabila memenuhi maka mereka akan diproses lanjut, yaitu wawancara khusus antara pembina mikro kredit dan calon anggota mikro kredit. Setelah melalui pemrosesan tersebut, maka calon-calon anggota tersebut digabungkan dengan kelompoknya, yaitu tetangga terdekat yang telah memenuhi syarat. Apabila mereka atau calon anggota tersebut tidak memenuhi prasyarat miskin kota atau memiliki penghasillan di atas kriteria yang telah ditetapkan, maka mereka tidak bisa ikut proses selanjutnya.

Setelah kelompok kecil tersebut terkumpul, yaitu berjumlah 5 peserta, maka mereka diwajibkan untuk ikut pelatihan selama 6 hari. Materi pelatihan tersebut di antaranya adalah pencatatan akuntansi sederhana untuk pedagang kecil, materi hikmah tentang pedagang, materi tentang peraturan mikro kredit beserta hafalan ikrar atau janji yang harus dilafazkan ketika pembukaan pertemuan kelompok dan penenutupannya.

Setelah terbentuknya kelompok, maka setiap anggota dari mikro kredit yang akan memperoleh bantuan pembiayaan, diminta untuk merancang proyek ekonomi masing-masing mengikuti kemahiran dan kemampuan. Apabila semua anggota kelompok setuju atas rancangan proyek bisnis tersebut, maka pembina kumpulan akan menyetujui pembiayaan mikro kredit dalam kelompok tersebut. Mikro kredit ini secara keseluruhan mengikuti syariah Islam seperti tidak adanya bunga, tanggung renteng anggota apabila ada anggota lain tidak memiliki kemampuan lagi untuk membayar hutang, dan dihapusnya hutang ketika si peminjam hutang dari anggota mikro kredit meninggal. Pengelola mikro kredit hanya menarik biaya administrasi guna mengelola mikro kredit. 


\section{Mikro Kredit di Kelurahan Petojo Utara}

Yayasan Mikro kredit yang pendiriannya dilaksanakan secara sederhana dengan nama Ikhtiar Islami, dengan metode aplikasi yang diambil dari AIM. Berikut gambaran singkat Ikhtiar Islami yang sudah diaplikasikan di tahun 2003-2005 di daerah kelurahan Petojo Utara Jakarta. Yayasaan Ikhtiar Islami dibangun guna melaksanakan kegiatan yang bersifat sosial seperti pemberian kredit kecil pada kaum dhuafa, santunan anak yatim, pengajian Islam, seminar, pelatihan, khitanan massal, dan aktivitas-aktivitas lainnya dalam rangka hari besar Islam.

Yayasan Ikhtiar Islami dibentuk bertujuan untuk mengurangi kemiskinan serta meningkatkan kesejahteraan melalui pemberian kredit kecil Qard al-Hasan (pinjaman kebajikan tanpa bunga) untuk membiayai kegiatan yang menambahkan pendapatan. Pendapatan Rp 750.000,-/bulan dengan tanggungan di bawah 4 orang atau Rp 1.200.000/bulan dengan tanggungan di atas 4 orang dan sanggup berusaha menambah pendapatan keluarga dengan usaha yang menguntungkan. Ikhtiar Islami menyediakan pemberian kredit kecil, mudah, cepat, dan rapi dalam aspek manajemen dengan asas tidak memerlukan jaminan, tidak memerlukan penjamin, dan tidak mengenakan bunga.

Bagi anggota rumah yang layak berdasarkan sensus kelayakan yang dibuat oleh manajemen yayasan dan pertemuan oleh pengurus, mereka perlu bersedia dikumpulkan dalam satu kelompok, yaitu terdiri dari 5 orang; wanita, dipercaya, dan bertanggung jawab; serta tidak memiliki hubungan persaudaraan. Pelatihan dilaksanakan selama 1 jam dalam jangka waktu 6 hari, bertujuan untuk memahami peraturan dan syarat-syarat pembiayaan. Pada akhir masa pelatihan, maka diuji kefahaman anggota kelompok tentang aturan Ikhtiar Islami dengan ujian tanya jawab perorangan. Setiap anggota wajib memiliki simpanan secara mingguan antara Rp 500,- hingga Rp 1000,- dengan rincian sebagai berikut:

Tabel 1 Rincian Jumlah Pembiayaan

\begin{tabular}{llc}
\hline $\begin{array}{c}\text { Jenis } \\
\text { Pembiayaan }\end{array}$ & \multicolumn{1}{c}{$\begin{array}{c}\text { Jumlah } \\
\text { Pembiayaan }\end{array}$} & $\begin{array}{c}\text { Tenggang Waktu } \\
\text { Pengembalian }\end{array}$ \\
\hline PIT -1 & Rp. $500.000,-$ & $12-24$ minggu \\
PIT - 2 & Rp. $\mathbf{8 0 0 . 0 0 0 , -}$ & $12-24$ minggu \\
PIT -3 & Rp. 1.200.000,- & 24-32 minggu \\
\hline
\end{tabular}

Ikrar memiliki tujuan mengingatkan setiap pengurus dan anggota yayasan Ikhtiar Islami untuk mengjadi asas amalan dan perbuatan setiap waktu. Ikrar ini haruslah dihafalkan dan diikrarkan setiap memulai dan mengakhiri pertemuan mingguan. Bunyi ikrarnya adalah sebagai berikut. Pertama, Ikrar Pengurus, yakni "Kami diamanahkan membantu keluarga sejahtera dengan menambah rezeki melalui pinjaman Qard al hasan yang dikeluarkan kepada mereka yang sanggup berusaha dan mempunyai proyek yang sempurna tanpa melihat suku, agama, jenis kelamin, pemahaman politik. Allah menjadi saksi segala yang kami lafazkan dan ikrarkan". Kedua, Ikrar Anggota, yakni "Adalah menjadi tanggung jawab kami kepada Allah untuk bekerja menambah rezeki, membantu anggota kelompok bila mendapat kesusahan, menggunakan keuntungan pinjaman untuk meningkatkan kesejahteraan keluarga, mewajibkan anak-anak terus bersekolah, dan membayar balik pinjaman setiap minggu. Allah menjadi saksi segala yang kami lafaz dan ikrarkan.”

Perempuan mungkin akan bergantung kepada laki-laki sebagai pengawal penghasilan tunai keluarga, namun tidak ada pengurangan tanggungjawab perempun untuk memenuhi keperluan utama bagi keluarganya. Karena dibatasi dalam lingkup rumah tangga, perempuan ditawari proyek pembangunan yang berasal dari dunianya sendiri - merajut, merenda, atau memproses makanan, dan pekerjaan yang lebih cocok bagi perempuan.. 


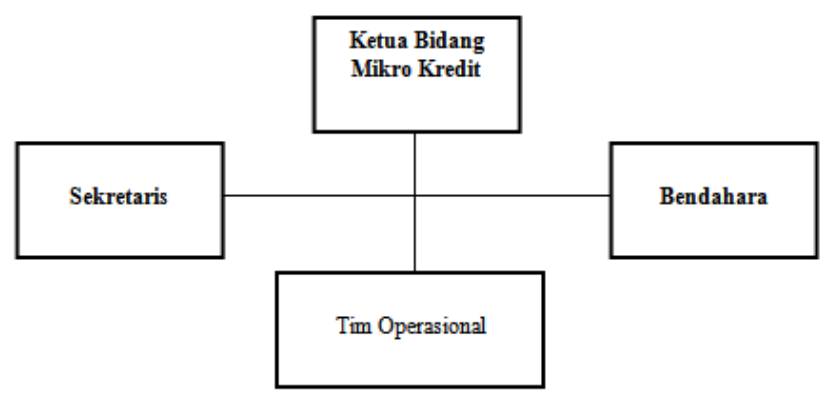

Gambar 2 Bentuk Organisasi Mikro Kredit

Dalam pelaksanaan tahap awal, dengan jumlah pinjaman sebesar Rp 500.000/orang didapatkan pelaksanaan mikro kredit pada pinjaman pertama sangat menghasilkan dan cepat perputaran modalnya, pengembalian modal telah berhasil dilaksanakan sesuai dengan jangka waktu yang telah disepakati. Oleh karena itu, kemudian dilaksanakan peminjaman dengan tahap kedua sebesar Rp 800.000,-/orang . Tapi masuk putaran kedua, para anggota mulai tersendat pembayarannya, dan terdapat peristiwa meninggalnya 2 orang anggota mikro kredit, dan penggusuran penjualan oleh aparat pemerintah diantara anggota mikro kredit. Pembayaran mulai tidak lancar dengan mulai enggannya anggota mikro kredit untuk hadir dalam pertemuan mingguan dengan berbagai alasan. Dalam kurun waktu terulur dan terlihat jelas, para anggota 75\% tidak lagi dan enggan untuk hadir apalagi membayar pinjaman.

\section{SIMPULAN}

Metode AIM ini sangat menarik dan dapat berujung pada keberhasilan apabila dari setiap anggota mikro kredit ini dapat diandalkan kejujuran dalam hal pemakaian keuangan, dengan mengutamakan pengembalian tepat waktu. Berdasarkan analisis dari sisi hasil penelitian, metode ini cocok diaplikasikan di daerah di mana kebanyakan masyarakatnya masih menganut kejujuran sebagai prinsip hidup utama. Dalam pandangan peneliti, ada beberapa faktor kurang berhasilnya program ini dilaksanakan, yaitu (1) Kurangnya pemahaman atas proses takafuli, yakni ketika ada rekan yang tidak mampu membayar hutang, maka para peserta lain harus menanggung hutang bersama. Dengan demikian, muncul keengganan untuk hadir dalam pertemuan mingguan; (2) Sikap mental. Dalam banyak kejadian, pemerintah daerah di Jakarta telah pula menjalankan program pemberdayaan masyarakat serupa, yakni memberikan pinjaman modal usaha bagi masyarakat dengan tanpa agunan, misalnya Jaringan Pengaman Masyarakat (JPM), ketika warga masyarakat tidak mampu mengembalikan dana pinjamannya ternyata tidak dilakukan upaya untuk menarik pinjaman tersebut. Lama kelamaan hal ini membentuk sikap mental masyarakat untuk tidak membayar; (3) Malas untuk bekerja; (4) Pendidikan yang rendah; (5) Kurang jujur dan tidak amanah dalam menggunakan pinjaman untuk usaha; (6) Tidak ada niat untuk mengembalikan hutang; (7) Tidak bisa memisahkan keuangan usaha dan kepentingan keluarga; (8) Meremehkan hutang; dan (9) Pemahaman agama yang kurang. 


\section{DAFTAR PUSTAKA}

Amanah Ikhtiar Malaysia. (1997). Laporan 10 tahun AIM 1987-1997.

Amanah Ikhtiar Malaysia. (2000). Risalah: Skim pembiayaan ikhtiar, edisi kelima. 